\title{
George Sand, CEuvres complètes: Les Sept Cordes de la lyre, Gabriel
}

\section{Lise Sabourin}

\section{OpenEdition}

1 Journals

Édition électronique

URL : http://journals.openedition.org/studifrancesi/4420

ISSN : 2427-5856

\section{Éditeur}

Rosenberg \& Sellier

Édition imprimée

Date de publication : 1 septembre 2016

Pagination : 348-349

ISSN : 0039-2944

\section{Référence électronique}

Lise Sabourin, « George Sand, Euvres complètes: Les Sept Cordes de la lyre, Gabriel », Studi Francesi [En ligne], 179 (LX| II) | 2016, mis en ligne le 01 septembre 2016, consulté le 17 septembre 2020. URL: http://journals.openedition.org/studifrancesi/4420

Ce document a été généré automatiquement le 17 septembre 2020.

\section{(c)}

Studi Francesi è distribuita con Licenza Creative Commons Attribuzione - Non commerciale - Non opere derivate 4.0 Internazionale. 


\title{
George Sand, CEuvres complètes: Les Sept Cordes de la lyre, Gabriel
}

\author{
Lise Sabourin
}

\section{RÉFÉRENCE}

GEORGE SAND, CEuvres complètes sous la direction de Béatrice Didier, 1840, Les Sept Cordes de la lyre, édition critique par Liliane Lascoux, et Gabriel, édition critique par Lucienne Frappier-Mazur, Paris, Honoré Champion, 2013, 406 pp.

1 Les deux écrits rassemblés dans ce volume 1840 des CEuvres complètes, présentés pour le premier par Liliane Lascoux (pp.9-44), pour le second par Lucienne Frappier-Mazur (pp. 185-208), ont en commun de montrer la dimension philosophique-politique du tournant des années 1838-39 dans la pensée de George Sand.

2 Les Sept Cordes de la lyre, écrites en août et septembre 1838, juste avant le départ pour Majorque avec ses enfants et Chopin, opère la synthèse complexe de sa lecture de Leibniz et Spinoza et de son panthéisme personnel. L'auteur choisit une forme exceptionnelle dans sa création, celle d'un drame fantastique, peu jouable vu son caractère composite. Il tient en effet du théâtre par son découpage en actes, son dialogue entre personnages, sa dimension musicale; mais aussi du roman par son intrigue amoureuse, son discours sur la conception artistique; et encore de l'épopée par sa voix poétique et sa vision des forces surnaturelles du monde. Sand privilégie dans cette œuvre, écrite rapidement dans l'enthousiasme après Spiridion et avant Consuelo, ce lyrisme mystique humanitaire qui cristallise les diverses influences qu'elle reçoit: Michel de Bourges et Pierre Leroux, ses «révélateurs» politiques et sociaux avec les saints-simoniens, en quête d'une langue musicale commune à toute l'humanité; Lamennais, pour son néo-christianisme rebelle qui l'a fait prendre conscience de son propre désaccord avec le catholicisme de son éducation; l'illuminisme de Lavater, à travers Balzac et sa Séraphîta; Ballanche, avec son Orphée pris entre le pur amour idéal d'Eurydice et la ménade passionnée Érigone; Diderot et Rousseau, ses penseurs bien 
aimés des Lumières; Hoffmann, pour son musicien fantastique, et Nodier, pour son juif Jonathas de La Fée aux miettes; Byron et Mickiewicz, dans les souffrances de Manfred et Konrad; Goethe surtout, dont elle a lu avec ardeur l'UrFaust et à qui elle répond après Corinne. Son Albertus en effet a quelques traits du docteur goethéen, sans pourtant en avoir le scepticisme orgueilleux, pris qu'il est de doutes avoués à ses disciples aux brefs noms bien germaniques, Wilhelm, Hanz et Carl. Quant à Hélène, celle qui lui fait parcourir en touchant les sept cordes métalliques de la lyre le chemin initiatique, expiatoire des horreurs commises par les humains, jusqu'à l'éternité de la création par amour, elle rappelle bien sûr Marguerite, mais aussi relève du second Faust, discuté dans Paris entre 1823 et 1832, traduit partiellement par Blaze dans la «Revue des deux mondes» en 1839. Quant à Méphistophélès, il incarne moins le mal absolu, fonctionnant plutôt en démon subalterne, logicien plus que tentateur, selon un refus de l'enfer très sandien. On comprend que Buloz se soit senti «écorché» par la lecture du manuscrit et que, malgré l'attachement à cette œuvre de Sand qui répondit avec vivacité à ses réticences, la critique soit restée si discrète à la parution de cette œuvre en mai 1839, même de la part de Liszt, alors très proche, qui pourtant s'en souviendra.

Balzac qui juge cet hapax mené d'un «train philosophico-républico-comunsico-PierreLerouscico-germanico-deisto-sandique» apprécie davantage Gabriel, écrit au retour de Majorque, lors du séjour marseillais de février à mai 1839, publié dans la «Revue des deux mondes» de juillet à août 1839. Ce «roman dialogué», constitué d'un prologue et de cinq parties (parfois désignées «actes» en prémices de l'adaptation théâtrale tentée jusqu'en 1859 et 1869), est également une œuvre atypique, entre dramaturgie et romanesque. Du théâtre relèvent la thématique du travestissement, les repères historiques qui font penser au scénario lancé par Sand pour Lorenzaccio tout en restant dans un flou de datation encadré par l'existence juridique du majorat; mais le manque de resserrement signe encore le roman, comme sans doute aussi le souvenir personnel d'une éducation virile donnée à la jeune Aurore par sa grand-mère. Situation ici prêtée à l'androgyne éponyme, fille élevée en garçon par un grand-père soucieux de préserver l'héritage dans la branche aînée, contre un petit-neveu digne des Octave et Lorenzo mussétiens, un Astolphe dont s'éprend Gabriel(le). Si le roman donne donc un exemple $\mathrm{du}$ «petit jeune homme» (selon la dénomination de Michèle Hecquet) typiquement sandien, cette femme travestie qui change la vie d'un autre par son message d'amour se souvient sans doute de la Christine de Dumas, du chevalier d'Éon, des Mémoires de Choisy ou de Casanova, de contes, tel le Marmoisan ou la fille en garçon, de La Fausse Suivante de Marivaux, mais aussi du Tasse, de l'Arioste et du Shakespeare de Comme il vous plaira. Par cette reprise du mythe de l'androgyne George Sand ne milite pourtant pas, comme le voudrait une actuelle théorie du genre, en faveur d'une ambiguïté de la définition identitaire, mais simplement constate les apports différents de l'inné et de l'acquis réservés par l'éducation féminine et l'organisation du mariage en son temps. 